\title{
Structural Relationship between Chinese Family Background and Cognitive ability -Focusing on Social Capital, Self-efficacy, and Interpersonal Variables at Home-
}

\author{
Yu Wenya ${ }^{1}$ \\ ${ }^{1}$ Student, College of Education, Kyungpook National University, Korea, qqsdwawa@163.com
}

\begin{abstract}
This study is aimed at analyzing the structural relationship between Chinese family background and cognitive ability through the analysis of Chinese Education Panel Survey (CEPS) data. The subjects of analysis were a total of 19,487 students in the first(10,279 students) and third grades(9,208 students) of Chinese middle schools, but 18990 people were included in the analysis through frequency analysis. Among them, 18,691 data was actually used when the analysis model was turned around, due to the Missing value. For the analysis, SPSS 24.0 and AMOS 24.0 programs were used, and the descriptive statistics and correlations for each variable were analyzed through SPSS24.0. Mean and standard deviation, kurtosis and skewness were confirmed through descriptive statistics. Next, the structural equation model was applied through AMOS24.0. In analyzing CEPS data, the study uses not only the students' academic achievement in language, mathematics, and English, but also their cognitive ability test scores. In addition, except for family background, the study considers variables at home such as social capital, personal variables such as self-efficacy levels, and school background variables such as interpersonal relationships. The result showed that first, family background had a distinct relationship with social capital, self-efficacy level, and cognitive ability. Among them, it was observed that one's family background had the most significant impact on cognitive ability, while it did not have a significant direct effect on interpersonal relationship ability. Second, it was observed that a family's social capital exerts a significant impact on self-efficacy level and peer relationship skills, but it was observed not to have a significant impact on one's cognitive abilities. Third, it was observed that one's self-efficacy level significantly impacts interpersonal relationship and cognitive abilities. Thus, the higher one's self-efficacy level, the higher the academic achievement. Finally, it was observed that peer relations do have a significant impact on one's cognitive ability. It promotes fairness of education and society in China by breaking down the phenomenon of intergenerational transmission caused by the family background, and provide intervention policies to narrow the gap between acquired educational resources and opportunities for students with different family backgrounds.
\end{abstract}

Keywords: Family Background, Social Capital at Home, Self-efficacy, Peer Relationship, Cognitive Ability

\section{Introduction}

\subsection{Research Necessity and Purpose}

Received: May 15, 2021; $1^{\text {st }}$ Review Result: July 01, 2021; $2^{\text {nd }}$ Review Result: August 20, 2021 Accepted: September 30, 2021 
According to modern human capital theory, human abilities and skills can be acquired through investment in human capital and productivity can be acquired through education. The biggest role in the distribution of income under the market economy is the ability and competitiveness of individuals in the labor market. In other words, high human capital can obtain a greater income in the labor market[1]. Moreover, it is cognitive ability that plays a tremendous role in the acquisition of an individual's socioeconomic status[2]. The cultivation of cognitive ability is mainly accomplished through education[3]. Students improve their cognitive ability through education in various settings at home and in school. Individual cognitive ability is not only a result of receiving education, but it also has an important influence on socioeconomic outcomes and behavior, which are the entire life cycle of an individual [4]. The cognitive ability and education that children gain during their school life have important implications for future earned income. In general, cognitive ability represents a student's learning ability, and the higher the likelihood of obtaining a higher educational background, the greater the educational effect. A study by Bettinger and Slonim found that people with higher cognitive abilities had better learning skills and future potential[5]. Hanushek and Wssmann found that high levels of cognitive ability reduce the rate of flucked students and low cognitive ability leads to high dropout rates[6]. Frederick studied the impact of cognitive abilities on economic behavior, and found that people with higher cognitive abilities were more rational in consumption and savings and more patient with investment[7]. Cognitive ability can predict a person's future educational achievement and wage level relatively accurately[8], and cognitive ability is also an important factor influencing intergenerational mobility[9] . However, because there exist different environments at home and different qualities of schools, the opportunities which students can acquire cognitive abilities do not equate. Therefore, the issue of inequality in cognitive abilities acquired by individual students in the current education system must be addressed in modern society.

In 2007, Zhang Wei, Li Dongping, Xiezhijie synthesized domestic and foreign studies to find that socioeconomic conditions at home have an effect on children's physical health, cognitive, emotional and behavioral condition, and act through channels such as children's physical and psychological conditions, material and social environment of family, and community and school conditions[10]. Coleman analyzed the factors influencing academic achievement of students of various races in the United States and found that the cause of the imbalance in children's development was due to the family. Since the family is very important for student development, the family background has an inevitable link to the development of student's cognitive ability[11]. Since the publication of Coleman Report, the correlation between socioeconomic status at home and educational achievement of children has aroused widespread and continuous interest, and research papers have been poured out in which family factors affect students' academic achievement. Since the 1970s, researchers have constantly improved the concept framework, survey indicators, and research methods. Also, they introduced mediatoring variables in addition to considering variables such as existing family background and economic level, and progressed the studies about the influence which family factors have on students' academic achievement. The socioeconomic status of the family has a positive correlation with cognitive abilities such as student attention and work memory, and students in the upper class have the ability to describe better thinking and interpret thoughts, and behavioral interactions between family members have a significant effect on a student's perception. Parents' participation and intergenerational closure in social capital are also helpful for children's growth and development, and are also remarkably helpful for students' cognitive abilities[12].

The family background plays a significant role in the development of students' cognitive abilities, and the socio-economic status of the family is related to students' cognitive abilities. Educational fairness is an important cornerstone of social equality and includes fairness in educational power, educational opportunities, academic achievement, and fairness in educational effects[13]. In real life, the child has a higher cognitive ability because a group with a better socioeconomic situation directly purchases high- 
quality educational resources to cultivate their children's abilities and provide them with a higher quality living learning environment in the long term. They help improve children's educational performance and socioeconomic status by highlighting their cognitive abilities. Therefore, this means that education is unfair to those who receive education in an alienated socioeconomic situation. Currently, China has fewer studies on cognitive ability, relatively single existing studies, and data on cognitive ability have been investigated in recent years, so it is very meaningful to identify the influencing factors of cognitive ability and establish effective intervention policies. This study is aimed to analyze the relationship between the family background and the cognitive ability of middle school students to prove the existing theory, while also analyzing the effect of student self-efficacy, school peer relations, and home social capital on cognitive ability. This is intended to help in comprehensively considering the influencing factors of cognitive ability, and can further develop students' cognitive ability to help not only themselves but also society as a whole.

\subsection{Research Question}

The research question of this study, which was established to achieve the necessity and purpose of the above-mentioned study, was set about how the structural relationship between family background, social capital, self-efficacy, peer relationships, and cognitive ability is. Therefore, the results obtained from this study are expected to produce the policies about solution of inequality, and contribute to resolutions about that.

\section{Theoretical Background}

\subsection{Concept of Cognitive Ability}

In China, ability is defined as the overall quality in accomplishing tasks and missions. Ability is a psychological feature that can directly influence the effectiveness of an activity and allows for the smooth completion of a task[14]. According to 《Modern Chinese Dictionary》, ability is described as the power used to process talent and work, and it is also a psychological characteristic required in managing and utilizing the knowledge and skills. According to the Naver Encyclopedia of Knowledge in Korea, ability is defined as a physical or psychological force which is used to perform a particular action, which can be learned or be innate. Abilities are often divided into either general and common skills, similar to intelligence, related to performing various tasks(especially cognitive or intellectual), or specialized skills related to the performance of specific tasks[15]. In summary, ability is a power that allows people to smoothly complete their tasks, and that power can be obtained through the learning process, or inherently since birth. The difference in the level of that power results in the difference in achievements. Abilities are categorized into general abilities which are commonly required activities and special competencies for the performance of highly specialized tasks.

According to the view of Traditional Human Capital Theory, one's ability had always been regarded as cognitive ability[16], and Chinese Encyclopedia of Science defines it as "The abilities which the human brain processes to store, and extract information." In other words, it is one's ability of figuring out composition, performance of a thing and its relation with others, power of development, direction and basic laws[17]. It mainly depends on cognitive ability that a person perceives the objective world and acquires lots of knowledge. According to Naver Knowledge Encyclopedia in Korea, cognitive abilities is referred as the abilities to acquire and utilize the gained knowledge by oneself. Cognitive abilities include mental capabilities such as understanding, reasoning, problem solving, criticism, and creativity[18]. 


\subsection{Factors Affecting One's Cognitive Ability}

'Congenital factors' such as gender, age, ethnicity, and parents, and 'acquired factors' such as the level of education, job experience, and economic conditions are all said to influence the cognitive abilities of Chinese[19]. Family background is one of the most important foundational factors influencing children's cognition and academic achievement[20]. Parent's low level of education or financial status often results in the poor academic achievement of their children during and after childhood. Swell et al. (2004) observed that children from upper social classes scored higher on cognitive tests than children from lower social classes[3]. This trend can be explained through the investigation of the difference in opportunities which the students are exposed to. Children from upper social class have more academic opportunities, as well as the continuous assistance and financial support from their parents throughout their studies. In addition, children from higher social classes are benefit more in improving cognitive skills as teachers can evaluate them at school more easily.

The family background affects the acquisition and improvement of cognitive abilities directly, but the degree of communication and joint activities between the parents and the children, parents' educational support for students and interests can be a vehicle, too. Therefore, it can be said that the magnitude of the influence of the family background on the student's ability acquisition is dependent on the social capital at home[21].

Coleman(1966) points out that as the close and positive relationship between the parents and children is maintained, the parents can utilize their physical, financial and intellectual abilities to help their children achieve academic success[22]. It was found that higher degree of communication and joint activities between the parents and the children leads to higher degree of supervision and leadership of parents over their children's academics, which ultimately has a more positive impact over the children's academics, allowing them to achieve better academic progress[23]. Conversely, if the parents' home social capital is used only at work or anywhere other than on the child, the influence of the family background on the child's cognitive abilities will be insignificant. In the case of adolescents with high social capital at home, the degree of development seen in cognition, emotion, and behavioral abilities are higher than that of adolescents with low social capital at home[24]. In addition, the higher the social capital is in the home, the higher the self-esteem and life satisfaction will be, and the lower the depression and hostility rate will be[25].

The most important factors influencing students' academic performance can be affected by their peer relationships in school, not only by their family background and social capital in household[26]. Good peer relation helps children and adolescents acquire social values, social abilities, smooth academic completion, and develop healthy cognition and character[27]. However, some studies show that maintaining close relationships with the peers in the same academic competition has a negative impact on academic performance[28], whereas some studies showed that peer relationships and students' academic performance are independent of one another[29]. Therefore, the effect of peer relations on students' academic performances remains controversial so further studies are required to fully determine its relationship.

From another perspective, the family background of a student may have an indirect involvement in peer selection and may lead to easier building of relationships with children of high-income family due to the close distance between the residences[30]. Investments in social capital in the home also helps establish peer relationships[31]. Parents' interest and involvement in their children is expected to convey their demands and expectations when children are making new friends through their expectations on the quality of education, thereby affecting the forming of student peer relationships[27]. Furthermore, in the situation of the division of Chinese provincial and rural dualization, the family register of parents affected the range of fellowship of children, the degree of acceptance among peers, and status. Generally it is not easy for left-behind children to be enthusiastic in building new relationships with his or her new 
peers.

One's perception and judgement of his or her own ability and growth of ability in each field such as an individual's physiology and psychology all start with family life. That is, the main effect factor and source of one's self-efficacy is family[32]. This sense of self-efficacy has a significantly greater impact on academic performance than other factors[33]. Qian Zhen(2008) expressed that high self-efficacy levels of middle school students have outstanding static directional expectation action, and that the higher the self-efficacy levels, the better the academic performance[34]. In addition, Jiao Li-ying(2009) found that the cultural degree of father and mother and the family's economic situation had a remarkable effect on the self-efficacy levels among middle school students[35]. The study of GuoRui, Deng Shusong, Liang jian-cheng, Yan ya-qiong, and Ma Ying-jiao(2009) also shows that intimacy, emotional expression, and warm understanding share self-efficacy levels of middle school students[36].

Based on the above prior studies, the following research investigates how social capital in household, self-efficacy and peer relationship affect the impact relationship between family background and cognitive ability.

\section{Research Method}

\subsection{Data and Samples}

This study used the data from the China Education Panel Survey (CEPS) of the National Survey Research Center at Renmin University of China (NSRC). The China Education Panel Survey (CEPS) is a long-term follow-up survey of approximately 20,000 participating students in the first year of middle school (10,279 students) and the third year (9,208 students) as of 2013-2014. Sampling was conducted from 2,870 prefectures in 34 provinces across China. The number of prefectures sampled was 28, of which 15 prefectures were wirelessly sampled, and three prefectures were nomadically sampled as regions that could represent "economically developed regions". The remaining ten prefectures were also sampled nomadically so that they could represent regions with many migrants. The final survey was conducted in 112 schools, and the results were collected wirelessly from 28 prefectures. The students to be surveyed were determined by wirelessly sampling two classes from each school. In the case of schools with two or less classes, all students in the school were surveyed.

\subsection{Variable Description and Research Model}

This study was conducted to analyze the relationship structure between students' cognitive abilities in the family background. This study aims to examine not only the family background, but also the individual variables such as self-efficacy, family social capital, and school variables such as peer relations. The variables(questions) used in this study are summarized as follows.

In most studies in China, determination of one's cognitive ability only depends on standardized language, mathematics, and English scores, which represents the intellectual ability such as IQ[37]. Therefore, objective variables are remarkably insufficient in measuring cognitive ability, so they cannot be trusted as the criteria of measuring students' cognitive ability. Therefore, in this study, among the questions contained in the Chinese Panel Survey data, the cognitive ability variable was set as a variable not only the student's academic achievement in language, mathematics, and English, but also the cognitive ability test score. For the family background, parents' level of education, and family economy level questions were set. As social capital variables, conversation between parents and children and participation in parent learning were set, and three self-efficacy parent questions and four peer relations questions were set. The research model set up to analyze the influence relationship between these variables is shown in [Fig. 1]. This model was established to examine how the structural relationship 
between family background and social capital, self-efficacy, peer relationship, cognitive ability is.

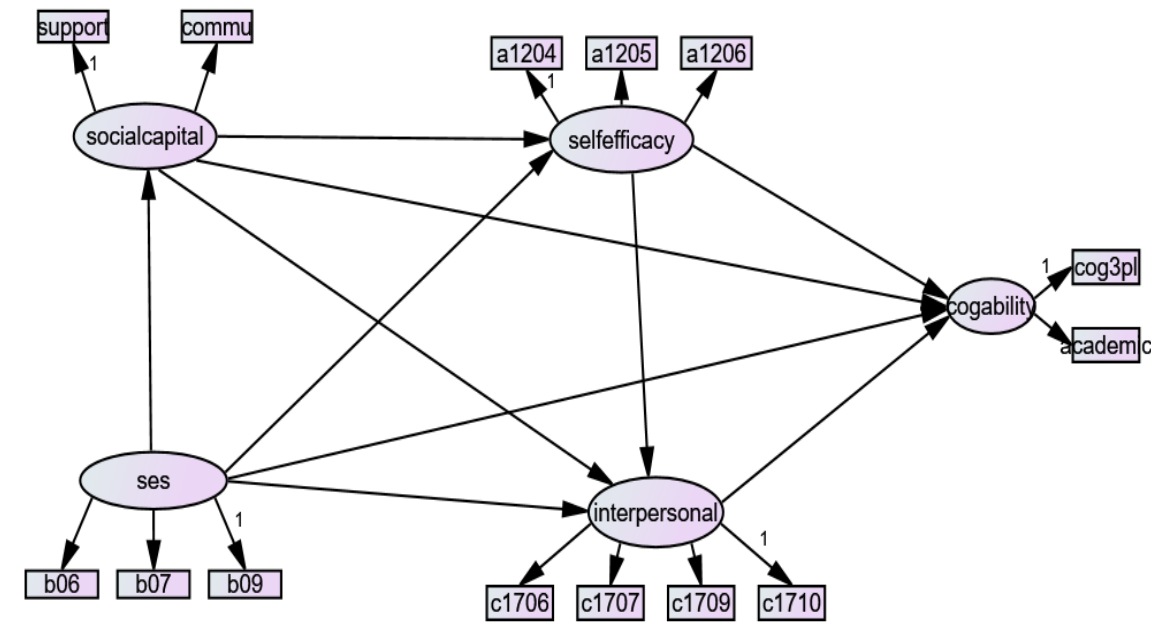

[Fig. 1] Research Model

[Table 1] Description of Major Variables

\begin{tabular}{|c|c|c|c|}
\hline Variable type & & Variable & Variable Description \\
\hline \multirow{2}{*}{$\begin{array}{l}\text { Dependent } \\
\text { Variables }\end{array}$} & \multirow{2}{*}{$\begin{array}{l}\text { Cognitive } \\
\text { Ability }\end{array}$} & $\begin{array}{l}\text { Cognitive Ability } \\
\text { Test Grade }\end{array}$ & \multirow{2}{*}{$\begin{array}{l}\begin{array}{l}\text { Cognitive Ability Test Standardization Score } \\
\text { (3PL model is used) }\end{array} \\
\begin{array}{l}\text { Chinese study, Mathematics study, English study score } \\
\text { (A total of } 150 \text { points in each subject) }\end{array} \\
\end{array}$} \\
\hline & & \begin{tabular}{|l|} 
Student \\
Grade
\end{tabular} & \\
\hline \multirow{5}{*}{$\begin{array}{l}\text { Independent } \\
\text { Variable }\end{array}$} & \multirow[t]{2}{*}{$\begin{array}{l}\text { Family } \\
\text { Background }\end{array}$} & Parents' Education Level & $\begin{array}{l}\text { 'I haven't received any education' = } 0 \text { years', } \\
\text { ' Elementary school }=6 \text { years', } \\
\text { 'Middle school }=9 \text { years", } \\
\text { 'Junior high school } / \text { technical school } / \text { vocational high school = } 11 \text { years', } \\
\text { 'Undergraduate school }=16 \text { years', } \\
\text { 'Master and above }=19 \text { years' }\end{array}$ \\
\hline & & \begin{tabular}{lrr|} 
Family's & Economic \\
Status(Economic & level \\
recognized by & the \\
student ) &
\end{tabular} & $\begin{array}{l}\text { 'Very difficult }=1 ", \quad \text { 'Slightly difficult }=2 ", \\
\text { 'Moderate }=3 ", \text { 'Not very difficult }=4 ", \\
\text { 'Not at all difficult = 5', } \\
\text { It is composed of a 5-point scale. }\end{array}$ \\
\hline & $\begin{array}{l}\text { The } \\
\text { Variables of } \\
\text { Home }\end{array}$ & Social Capital at Home & $\begin{array}{l}\text { "Have parents ever urged students to study? / Checked their homework? / } \\
\text { Helped students study?" About Not at all =1, About } 2 \text { days = 2, } \\
\text { About } 4 \text { days }=3 \text {, Almost every day }=4 \\
\text { When asked, "Do you often have conversations with your child related to the } \\
\text { following?" 'talk about school, conversation about friends, conversation } \\
\text { about teachers, conversation about yourself' no=1, 'It is normal.'=2, 'Yes = } 3 \\
\text { measured. }\end{array}$ \\
\hline & $\begin{array}{l}\text { Personal } \\
\text { Variable }\end{array}$ & Self-efficacy Level & $\begin{array}{l}\text { "I can clearly explain my own opinions" "My ability to react quickly" } \\
\text { "I accept new knowledge quickly" } \\
\text { Each response is: not at all, not very much, usually, definitely. }\end{array}$ \\
\hline & $\begin{array}{l}\text { School } \\
\text { Background } \\
\text { Variable }\end{array}$ & $\begin{array}{l}\text { Interpersonal } \\
\text { Relationship }\end{array}$ & $\begin{array}{l}\text { "Most classmates are nice to me." } \\
\text { "I think it's easy to get along with people." } \\
\text { "I often participate in activities organized by schools/classes." } \\
\text { The question "I feel kind to the people of this school" is not at all - not so } \\
\text { much -generally yes - very much so. }\end{array}$ \\
\hline
\end{tabular}




\subsection{Method of Analysis}

This study mainly used AMOS 24.0 and SPSS 24.0 programs, and a structural equation model is performed on sample data to explore the structural effect of the family background on the student's cognitive ability. First, SPSS 24.0 and AMOS 24.0 programs were used, and the descriptive statistics and correlations for each variable were analyzed through SPSS24.0. Mean and standard deviation, kurtosis and skewness were confirmed through descriptive statistics. Next, the structural equation model was applied through AMOS24.0.

\section{Research Results}

\subsection{Descriptive Statistics and Correlation between Variables}

The results obtained from using different statistics test to observe the trend between variables, and to observe the data's general reliability are shown in [Table 2].

[Table 2] Correlation and Descriptive Statistics

\begin{tabular}{|c|c|c|c|c|c|c|c|c|c|c|c|c|}
\hline & b06 & b07 & b09 & commun & support & a1204 & a1205 & a1206 & c1706 & c1707 & c1709 & c1710 \\
\hline b06 & 1 & & & & & & & & & & & \\
\hline b07 & $.666^{* *}$ & 1 & & & & & & & & & & \\
\hline b09 & $.273^{* *}$ & $.262^{* * *}$ & 1 & & & & & & & & & \\
\hline commun & $.176^{* *}$ & $.176^{* *}$ & $.103^{* *}$ & 1 & & & & & & & & \\
\hline support & $.200^{* *}$ & $.179^{* * *}$ & $.107^{* * *}$ & $.331^{* *}$ & 1 & & & & & & & \\
\hline a1204 & $.081^{* *}$ & $.070^{* *}$ & $.071^{* *}$ & $.168^{* *}$ & $.126^{* *}$ & 1 & & & & & & \\
\hline a1205 & $.159^{* *}$ & $.142^{* *}$ & $.120^{* *}$ & $.152^{* *}$ & $.147^{* *}$ & $.472^{* *}$ & 1 & & & & & \\
\hline a1206 & $.154^{* *}$ & $.143^{* *}$ & $.115^{* *}$ & $178^{* *}$ & $.131^{* *}$ & $.417^{* *}$ & $.565^{* *}$ & 1 & & & & \\
\hline c1706 & $.098^{* * *}$ & $.096^{* *}$ & $.118^{* *}$ & $.195^{* *}$ & $.108^{* * *}$ & $.168^{* *}$ & $.168^{* *}$ & $.201^{* *}$ & 1 & & & \\
\hline c1707 & $.096^{* *}$ & $.091^{* *}$ & $121^{* *}$ & $.198^{* *}$ & $.114^{* *}$ & $.204^{* *}$ & $.211^{* * *}$ & $.212^{* *}$ & $.662^{* *}$ & 1 & & \\
\hline c1709 & $.154^{* *}$ & $.129^{* * *}$ & $.134^{* * *}$ & $.269^{* *}$ & $.190^{* * *}$ & $.193^{* *}$ & $.209^{* * *}$ & $.211^{* * *}$ & $.371^{* * *}$ & $.396^{* *}$ & 1 & \\
\hline c1710 & $.131^{* *}$ & $.117^{* *}$ & $.111^{* *}$ & $.280^{* * *}$ & $.185^{* *}$ & $.184^{* *}$ & $.169^{* *}$ & $.210^{* *}$ & $.482^{* *}$ & $.470^{* * *}$ & $.498^{* * *}$ & 1 \\
\hline $\mathrm{N}$ & 19,129 & 19,093 & 18,691 & 19,411 & 19,313 & 18,686 & 18,694 & 18,529 & 19,270 & 19,275 & 19,254 & 19,120 \\
\hline Mean & 3.80 & 4.17 & 2.99 & 4.00 & 2.21 & 3.10 & 2.98 & 2.98 & 3.26 & 3.16 & 2.74 & 2.93 \\
\hline $\begin{array}{l}\text { Standard } \\
\text { deviation }\end{array}$ & 1.96 & 1.98 & .55 & 1.04 & 1.03 & .81 & .78 & 80 & .80 & .84 & 1.01 & 92 \\
\hline Skewness & .921 & .774 & .317 & -.043 & 424 & -.591 & -.436 & -.427 & -1.042 & .855 & .295 & .531 \\
\hline Kurtosis & -.298 & -.712 & 2.950 & -.714 & -1.055 & -.264 & -.224 & .359 & .722 & 182 & -1.035 & .578 \\
\hline
\end{tabular}

\subsection{Goodness-of-fit of the Model}

Several indicators used to determine the suitability of the study model established in this study and their review results are summarized in [Table 3]. The verification reacts sensitively according to the sample size, so there is a problem in that the fit for the same model is evaluated differently or the simplicity of the model is not considered. Therefore, this study uses the TLI (Tucker-Lewis Index), the CFI (Comparative Fit Index), and the RMSEA (Root Mean Square Error of Approximation) as the indices for determining the fit of the model. These indices are beneficial as they are not sensitively affected by the sample size, and TLI and RMSEA are known to be appropriate for evaluating a research model because they also consider the simplicity of the model. In general, if CFI and TLI are equal to or greater than .9, while RMSEA is equal to or less than .05, the result is said to be a good fit. While the result is said to be an appropriate fit if the value of CFI and TLI is below .08[38]. The goodness-of-fit 
indices obtained from this study model are TLI. 903, CFI. 938, RMSEA. 0.056, indicating that the proposed model shows an appropriate fit with the used data.

[Table 3] Goodness of Fit of the Research Model (N=19487)

\begin{tabular}{|c|c|c|c|c|c|}
\hline & & DF & CFI & TLI & RMSEA \\
\hline Model & 4220.411 & 67 & .938 & .903 & .056 \\
\hline
\end{tabular}

\subsection{Analysis Results for Structural Models}

[Table 4] Analysis Results for Structural Models

\begin{tabular}{|c|c|c|c|c|c|}
\hline Parametric & Non-standardized & Standardized & S.E. & C.R. & $\mathrm{P}$ \\
\hline Ses-->cogability & .139 & .384 & .004 & 31.759 & $* * *$ \\
\hline Social capital-->cogability & .020 & .018 & .017 & 1.185 & \\
\hline Self efficacy--> cogability & .117 & .097 & .014 & 8.461 & $* * *$ \\
\hline Interpersonal--> cogability & .182 & .195 & .011 & 16.420 & $* * *$ \\
\hline Ses--> social capital & .120 & .376 & .004 & 27.776 & $* * *$ \\
\hline Social capital-->self efficacy & .291 & .312 & .014 & 21.476 & $* * *$ \\
\hline Ses-->self efficacy & .036 & .119 & .003 & 10.859 & $* * *$ \\
\hline Social capital-->interpersonal & .420 & .346 & .018 & 23.658 & $* * *$ \\
\hline Ses-->interpersonal & .001 & .002 & .004 & .182 & \\
\hline Self efficacy-->interpersonal & .329 & .252 & .014 & 23.507 & $* * *$ \\
\hline
\end{tabular}

[Table 4] Summarizes the analysis result of the structural model which explains the relationship between the family background and cognitive ability of Chinese middle school students. Because the selected structural equation model was evaluated to be an appropriate and reliable model, as the estimation results for each variable shows, family background has a clear relationship with social capital at home, self-efficacy level, and cognitive abilities and it was found to be the most influenced variable to cognitive ability (.384). However, it was observed that the family background did not have a meaningful effect on interpersonal relationships. Specifically, it was found that the higher the parent's educational background and family's economic level the higher the levels of children's cognitive abilities, self-efficacy levels, and a closer relationship with parents. This implies that lack of financial or resource support from the parents may lead to difficulties in maintaining a good relationship between the parents and the children.

Next, it was found that social capital at home exerts a significant effect on self-efficacy levels and peer relationships. However, it was found that social capital at home did not have a remarkable impact on cognitive abilities. In addition, it can be seen that self-efficacy levels have significant impact on interpersonal relationships and cognitive abilities.

\subsection{Effect Decomposition}

[Table 5] Effect Decomposition

\begin{tabular}{|c|c|c|c|c|}
\hline $\begin{array}{c}\text { Independent } \\
\text { Variable }\end{array}$ & $\begin{array}{c}\text { Subordination } \\
\text { Variable }\end{array}$ & Total Effect & Direct Effect & $\begin{array}{c}\text { Indirect } \\
\text { Effectiveness }\end{array}$ \\
\hline \multirow{3}{*}{ Family Background } & Social Capital & .376 & .376 & .000 \\
\cline { 2 - 5 } & Self-efficacy & .237 & .119 & .117 \\
\cline { 2 - 5 } & Interpersonal & .192 & .002 & .190 \\
\cline { 2 - 5 } & Cognitive Ability & .452 & .384 & .067 \\
\hline
\end{tabular}




\begin{tabular}{|c|c|c|c|c|}
\hline \multirow{3}{*}{ Social Capital at Home } & Self-efficacy & .312 & .312 & .000 \\
\cline { 2 - 5 } & Interpersonal & .425 & .346 & .079 \\
\cline { 2 - 5 } & Cognitive Ability & .131 & .018 & .113 \\
\hline \multirow{2}{*}{ Self-efficacy } & Interpersonal & .252 & .252 & .000 \\
\cline { 2 - 5 } & Cognitive Ability & .146 & .097 & .049 \\
\hline Interpersonal & Cognitive Ability & .195 & .195 & .000 \\
\hline
\end{tabular}

When looking at the results of decompositions of the effects of the estimates of the structural equations presented in [Table 5], the effect of the family background on cognitive ability was 0.452 , showing the greatest effect, which can be considered as the result proving the importance of the family background. Specifically, the direct effect was calculated to be 0.384 , while the indirect effect was calculated to be 0.067 .

Next, the effect of social capital at home on cognitive abilities was calculated to be 0.131 as the whole effect which consists of the direct effect, 0.018 , the indirect effect, 0.113 . The number representing the effect of self-efficacy levels on cognitive abilities was found to be 0.146 as a whole, and it consists of the direct effect, 0.097, and the indirect effect, 0.049. Finally, the number describing the effect of peer relationship on cognitive abilities was 0.195 as a whole, and it consists of the direct effect, 0.195 and the indirect effect was not observed.

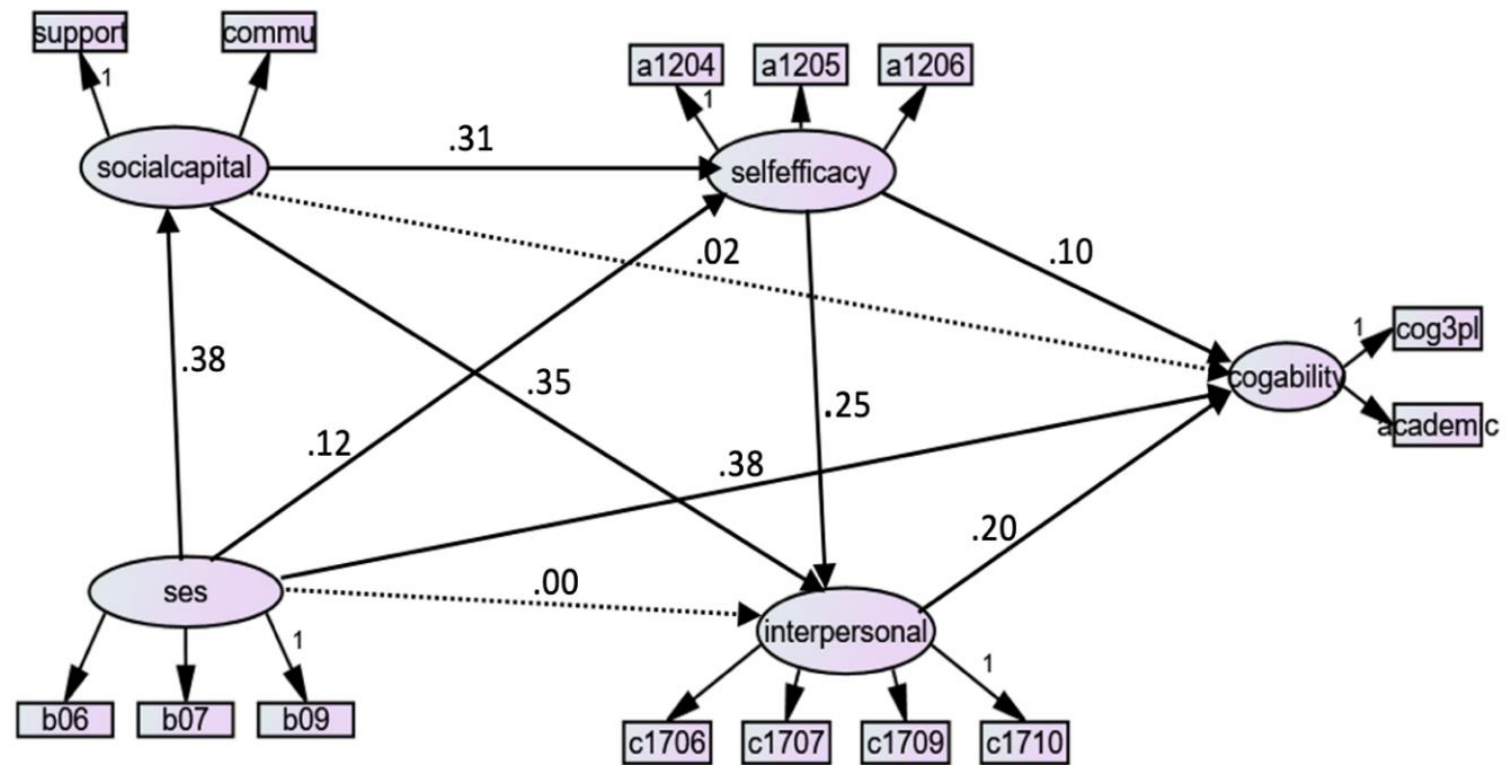

[Fig. 2] Concisely Shows the Above Structural Model Estimation Results

\section{Conclusion and Discussion}

\subsection{Conclusion}

Many studies have been looking into the problem of children's ability development from the perspective of individual and family backgrounds, especially in relation to the development of cognitive abilities. There are many possibilities to investigate how the family background works on the intermediate mechanisms of children. Based on the first round of data obtained by using CEPS national data, this study analyzed the relationship between middle school students' family background and their 
cognitive abilities involving the cognitive ability test scores, individual variable such as self-efficacy, household variable such as social capital at home, and school variable such as peer relationships. For this research, the results obtained from the analysis results in light of previous studies are as follows.

First, the family background was observed to have a significant relationship with social capital at home, self-efficacy level, and cognitive ability, and it has been found to have the strongest influence on cognitive ability among them. These results are in parallel with previously conducted studies Jiao Liying(2009)[35], and are also consistent with the previous study of Kim Kyung-geun, Hyun Jiyoung(2015) of Korea[39]. On the other hand, the results of the family background having no significant effect on peer relationships are in disagreement with previous studies(Yang Bu, Zhu Qiong, 2013)[27]. In addition, the results are inconsistent with the data obtained from a previous study(Lee Yang-sook, 2008)[40], which concluded that middle and upper classes of Korea's population have higher peersatisfaction and relationship compared to the lower class families.

Second, social capital at home has shown to have significant impact on self-efficacy and peer relationships. This result is in agreement with previously conducted studies(Froiland et al., 2013)[31] and the studies of Kim Kyung-sik, Lee Hyun-chul(2010)[41]. On the other hand, the results showing that social capital in the home doesn't have a meaningful impact on cognitive ability are inconsistent with the results of prior studies.

Third, self-efficacy has a significant effect on peer relationships and cognitive abilities. These findings are consistent with the previous Chinese studies of Qian Zhen(2008)[34] and previous Korean studies of Jung Young-hye(2013)[42].

Finally, peer relations have been found to have a significant effect on cognitive abilities. These results are consistent with previous studies Yang Bu, Zhu Qiong(2013)[27] and those of Korea Kim Kyung-sik, Lee Hyun-chu(2010)[41].

\subsection{Discussion}

First, it showed whether in China or Korea, the inequality in society is rapidly growing. Family background has a great influence on children's academic achievement, and it has been consistently reported that the greater the background of the family is, the higher the level of their children's academic performance is. The higher the family socio-economic background, the more positive the child's relationship with their parents, the better the self-efficacy, peer relationship and the higher the grade. However, a superior family background helps children obtain better educational attainment by improving their cognitive abilities, but, some poor people are too busy making ends meet to spend more money and energy on their children's education. This is contrary to educational equality, so additional help to socially inferior families should be provided, ensuring that children from all families have the opportunity to develop cognitive abilities. In this study, although the family background did not significantly affect the child's interpersonal relationships, it is ambiguous to clearly conclude whether the bad family background causes the separation of the peer groups formed among students. A study by Adalbert, et al.(2008) found that it was easier for two people from the same class to form peer relationships[30]. However, since this study did not look at the average family background of different peer groups, whether the phenomenon in which students from the same family background gather to form each other's peer group cannot be verified. In other words, a child from an upper class family background and a child from a lower class family background may each develop their own peer relationships with those similar to them. Therefore, it cannot be simply concluded that the family background does not affect the formation of interpersonal relationships. In addition, other influence mechanisms exist, like contributing to the separation of peer groups, therefore further studies and investigations are required. 
Second, the effects of social capital at home has continuity and scalability. Personality traits formed during family intercourse can spread widely outside the home. It particularly works strongly when interacting with peers. On the other hand, the reason why social capital at home does not have a meaningful effect on cognitive ability is probably due to the 'resources dilution model' theory. Blake(1981) presented the 'resources dilution model', stating that capital within a household is finite and may give adverse effects to the degree of education which an individual receives depending on the number of children in the family[43]. In this study, data from CEPS shows that the proportion of single child takes up only $43.41 \%$ of object of investigation. According to the "Resources Dilution Model", large number of siblings can lessen the opportunities of interaction between parents and each child, reducing the parental interest that each one can receive. This may affect the social capital of each child and the achievement of their education. Moreover, this study showed that although social capital does not directly affect cognitive ability, it affects one's cognitive ability by improving self-efficiency, an individual factor, and forming peer relationship positively.

Third, when students get positive evaluations, they set positive attitudes. Therefore, when communicating and interacting with others, they can start new human interchange with a positive attitude, bringing magnitude to things further[44]. This paper also confirmed that the higher the selfefficacy, the higher the academic achievement.

Finally, peer relations have been found to have a significant effect on cognitive abilities. However, the research conducted by Ma Dong-Yue(2019)[28] in China showed that peer relations do not have positive impact on academic achievement. That students with better academic performance tend to rank themselves in their classes, do not value socializing with their peers, and devote too much time and energy on studying. Excellent students frequently show indifference to other classmates. Ma DongYue(2019)[28] shows changes in the impact of peer relations on academic performance. The reason behind this may be due to the current era which prioritizes on the concept of grade supremacy, which is observed to be seriously progressing in the Chinese society. Under the "grade supremacy" evaluation system, only the 'test score' category became the most important evaluation standard. Sometimes a student's moral level is ridiculously determined by his or her score. Therefore, students' other qualities remarkably weakened, such as becoming a 'machine' which can only take tests. It can be said that this violates the wishes of Chinese education and the true meaning of education. Both schools and parents should not forget the true purpose of education. The ultimate goal of education is to nurture people with healthy mental health and personality, and to ensure that children have a sound mind, emotion, collective consciousness and responsibility. These are more important than just pursuing grade.

The results and implications of this study are summarized above, and finally, based on the limitations of this study, the direction and specific suggestions of subsequent studies would be suggested below.

\subsection{Proposal}

The research conclusion of this paper revealed that there is a difference in cognitive ability according to family background. However, this goal of reducing cognitive differences cannot be achieved in the short term and must be undertaken in several ways.

First, the degree of educational level of parents is already formed and cannot be changed, but parents can strive to create a good family education environment by improving their talents and planting the right view of home education. parents should connect home education with school and social education, so that students can acquire knowledge in an external environment and promote the overall improvement of students' cognitive abilities in a scientific and effective way.

Second, in the situation where the household economic level is different, the government should help the economic and educational resources to improve the family environment by shifting economic and educational resources to the lower social class. The cognitive ability gap can be reduced only by reducing 
inequality of opportunity and inequality in educational resources through policy support. The state should also prevent families with high family social and economic status from using their resource advantage to send their children to key middle school. Only when the opportunity for admission to education is fair can the lower social class move to the higher social class.

Third, under the constraints of home education resources, the increase in childbirth dilutes the input of home education, which does not help improve adolescents' cognitive ability and accumulation of human capital. The government should focus on multi-child families. Subsidy schemes should be designed to provide different levels of cash or financial assistance directly to families with different economic circumstances, to optimize resource allocation, and to close the gap between classes.

The research in this paper has the following problems due to the limitations of time and individual ability, and research on the future can find contact points in the following two aspects.

(1) The use of CEPS data for research samples is authoritative, but the factors affecting cognitive ability change over time. Due to the lack of sample size and related data, this study adopts only data for the year 2013-2014, making it difficult to estimate the trend of dynamic changes between variables. In addition, since it is data from 2014, there may be differences from the current social situation. Therefore, subsequently, through educational follow-up data after 2015, the elements that affect cognitive ability should be discovered in more depth through dynamic research. More realistic and reliable reference comments to narrow the cognitive gap should be provided.

(2) The variables of the study should be abundant. The effect on a child's cognitive ability can have many other causes in addition to the family background, and this study only focused on the family background. Future research can analyze and interpret cognitive abilities in detail by utilizing internal resources of schools in a situation where more data and samples can be obtained. In addition, the family background has various methods and influencing factors depending on the type of child, so on future study, it will be possible to analyze the types of children according to the Chinese family register. These issues are significant in how to efficiently allocate educational resources and require more attention in future research.

\section{References}

[1] Z. J. He, X. J. Wang, The Return to Cognitive and Non-cognitive Skills: Empirical Evidence from PIAAC, Research on Economics and Management, (2017), Vol.38, No.5, pp.66-74, DOI: 10.13502/j.cnki.issn1000-7636.2017.05.007

[2] Z. H. Wang, Estimating the Return to Education with Cognitive and Non-cognitive Ability, Education and Social Sciences, Hunan University, Master's Thesis, (2016)

[3] W. H. Sewell, R. M. Hauser, K. W. Springer, T. S. Hauser, As We Age: A Review of the Wisconsin Longitudinal Study, 1957-2001, Research in Social Stratification and Mobility, (2003), Vol.20, pp.3-111, https://doi.org/10.1016/S02765624(03)20001-9

[4] G. Y. Hang, Y. Xie, China People's Livelihood Development Report 2013, Peking University Press, (2013)

[5] E. Bettinger, R. Slonim, Patience among children, Journal of Public Economics, (2007), Vol.91, No.1-2, pp.343-363, https://doi.org/10.1016/j.jpubeco.2006.05.010

[6] E. A. Haushek, L. Wssmann, The role of cognitive skills in economic development, Journal of economic literature, (2008), Vol.46, No.3, pp.607-668.

[7] S. Frederick, Cognitive reflection and decision making, Journal of Economic Perspectives, (2005), Vol.19, No.4, pp. 25-42, DOI: $10.1257 / 089533005775196732$

[8] Y, Zhou, X. J. Liu, Cognitive Ability and Family Entrepreneurship: An Empirical Analysis Based on Data from the Chinese Family Tracking Survey (CFPS), Economic Dynamics, (2007), No.2, pp.66-75. 
[9] J. Blanden, P. Gregg, L. Macmillan, Accounting for Intergenerational Income Persistence: Noncognitive Skills, The Economic Journal, (2007), Vol.117, No.519, pp.C43-C60, https://doi.org/10.1111/j.1468-0297.2007.02034.x

[10] W. Zhang, D. P. Li, Z. J. Xie, Low socioeconomic status and child development, Journal of South China Normal University, (2007), No.6, pp.104-114, p.118, p.160.

[11] J. S. Coleman, Equality of Educational Opportunity, NATIONAL CENTER FOR EDUCATIONAL STATISTICS (DHEW), (1966)

[12] C. Desforges, A. Ahouchaar, The Impact of Parental Involvement, Parental Support and Family Education on Pupil Achievement and Adjustment: A Literature Review, Department for Education and Skills, (2003), pp.23-25.

[13] J. C. Xia, Thoughts on Educational Fairness, Academic Exchange, (2004), No.7, pp.161-163.

[14] https://baike.baidu.com/item/能力/33045?fr=kg_qa, Jan 25 (2021)

[15] https://terms.naver.com/entry.nhn?docId=510357\&cid=42126\&categoryId=42126, Jun 29 (1995)

[16] H. Y. Zhang, A Review of Jacks Heckman's Theory of Human Capital Investment-The Role of Non-cognitive Theory in the Labor Market, Communication of Finance and Accounting, (2010), No.30, pp. 73-75, DOI : 10.16144/j.cnki.issn1002-8072.2010.30.048

[17] https://baike.baidu.com/item/认知能力/1440086, Jul 17 (2021)

[18] https://terms.naver.com/entry.nhn?docId=1944462\&cid=41989\&categoryId=41989, Jan 10 (2000)

[19] R. Z. Wang, C. Liu, Nature versus Nurture: How Is Chinese Cognitive Ability Influenced, Journal of Lanzhou University, Social Sciences, (2016), Vol.44, No.2, pp.89-102, DOI: 10.13885/j.issn.1000-2804.2016.02.012

[20] R. H. Bradley, R. F. Corwyn, Socioeconomic status and child development, Anula Review of Psychology, (2002), Vol.53, pp.371-399, DOI: 10.1146/annurev.psych.53.100901.135233

[21] G. G. Kim, Social capital within the family and the academic achievement of children, Korean Journal of Sociology of Education, (2000), Vol.10, No.1, pp.21-40.

[22] J. S. Coleman, Equality of Educational Opportunity, (1966), https://doi.org/10.3886/ICPSR06389.v3

[23] L. P. Juang, R. K. Silbereisen, The Relationship between Adolescent Academic Capability Beliefs, Parenting and School Grades, Journal of Adolescence, (2002), Vol.25, No.1, pp.3-18, DOI: 10.1006/jado.2001.0445

[24] Y. Hu, J. Han, X. G. Chen, S. P. Yang, Y. H. Xu, S. Xie, W. W. Liu, Research on the mental health status of rural leftbehind children in Macheng, Hubei province and its correlation with social capital, Chinese Journal of Epidemiology, (2014), Vol.35, No.1, pp.31-34.

[25] Q. Wu, L. A. Palinkas, X. He, Social Capital in Promoting the Psychosocial Adjustment of Chinese Migrant Children: Interaction across Contexts, Journal of Community Psychology, (2011), Vol.39, No.4, pp.421-442.

[26] J. S. Coleman, Equality of educational opportunity, Equity \& Excellence in Education, (1968), Vol.6, No.5, pp.19-28, https://doi.org/10.1080/0020486680060504

[27] B. Yang, Q. Zhu, Analysis on the Influencing Factors of the Companion Relationship of Junior High School Students, Peking Universal Education Review, (2013), Vol.11, No.3, pp. 99-117.

[28] D. Y. Ma, A Study on the Relationship between Parent-child Relationship, Peer Relationship and Academic Achievement of Junior Middle School Students, Qufu Normal University, China, Master's Thesis, (2019)

[29] L. Yu, The influence of the Parents-children communication, Companion relationship and Teacher-student relationship to learning achievement of the students in high school, Northeast Normal University, China, Master's Thesis, (2008)

[30] A. Mayer, S. L. Puller, The old boy (and girl) network: Social network formation on university campuses, Journal of Public Economis, (2008), Vol.92, No.1-2, pp.329-347, https://doi.org/10.1016/j.jpubeco.2007.09.001

[31] J. M. Froiland, A. Peterson, M. L. Davison, The long-term effects of early parent involvement and parent expectation in the USA, School Psychology International, (2013), Vol.34, No.1, pp.33-50, 
https://doi.org/10.1177/0143034312454361

[32] A. Bandura, Self-efficacy: Implementation of control(Volume1), Shanghai East China Normal University Press, (2003)

[33] B. Li, J. L. Yang, Relations of Time Management Disposition, Self-efficiency, Attribution of Junior School Student to Academic Achievement, Psychological Exploration, (2004), No.4, pp.67-71.

[34] Z. Qian, A Study on the Relationship of Parenting Style Academic Attribution Academic Self-efficacy and Academic Achievement among Junior Middle School Students, Huazhong Normal University, China, Master's Thesis, (2008)

[35] L. Y. Jiao, The Influence of Family Environment and Self-Efficacy on Adolescent's Creative Scientific Problem Finding, Shanxi Normal University, China, Master's Thesis, (2009)

[36] R. Guo, S. S. Deng, J. C. Liang, Y. Q. Yan, Y. J. Ma, Influence of family factors on self-efficacy of the middle school students in Baise City, Journal of hygiene research, (2009), Vol.38, No.3, pp. 320-322, DOI : 10.19813/j.cnki.weishengyanjiu.2009.03.022

[37] L. Li, W. L. Zhao, A Study on the Impact of Family Background and Cultural Capital on Cognitive and Non-cognitive Ability, Dong Yue Tribune, (2017), Vol.38, No.4, pp.142-150, DOI : 10.15981/j.cnki.dongyueluncong.2017.04.017

[38] S. H. Hong, The Criteria for Selecting Appropriate Fit Indices in Structural Equation Modeling and Their Rationales, Clinical Psychology in Korea: Research and Practic, (2000), Vol.19, No.1, pp.161-177.

[39] H, S. Kim, K. K. Kim, J. H. Shim, Structural relationships between family background, social capital in the family and at school, and educational aspirations, Korean Journal of Sociology of Education, (2018), ), Vol.28, No.2, pp.2755, DOI:10.32465/ksocio.2018.28.2.002

[40] Y. S. Lee, Analysis of the Relationship among Children's Self-Perceived Communication Style with Parents, SelfEfficacy and School Adjustment, Chuncheon National University of Education, graduate school of education, Master's Thesis, (2008)

[41] K. S. Kim, H. C. Lee, The Longitudinal Relationship between Students` Human Relations(Parents-Children Relations, Teacher-Student Relations and Peer Relations)as Social Capital and Academic Achievement, Secondary Education Research, (2010), Vol.58, No.1, pp.203-225, DOI : 10.25152/ser.2010.58.1.203

[42] Y. H. Jung, (The)relationships among self-examination, self-efficacy, and academic performance, Dankook University, Master's Thesis, (2013)

[43] J. Blake, Family Size and the Quality of Children, Demography, (1981), Vol.18, No.4, pp.421-442, https://doi.org/10.2307/2060941

[44] A. Bandura, Self-efficacy mechanism in human agency, American Psychologist, (1982), Vol.37, No.2, pp.122-147, https://doi.org/10.1037/0003-066X.37.2.122 